\title{
Penerapan Metode K-Means pada Data Penduduk Miskin Per Kecamatan Kabupaten Blitar
}

\author{
Dede Nor Alfiansyah ${ }^{* 1}$, Vinna Rahmayanti Setyaning Nastiti ${ }^{2}$, Nur Hayatin ${ }^{3}$ \\ 1,2,3 Universitas Muhammadiyah Malang \\ dedenoralfiansyah@gmail.com ${ }^{* 1}$, vinna.nastiti@gmail.com ${ }^{2}$, noorhayatin@gmail.com ${ }^{3}$
}

\begin{abstract}
Abstrak
Kemiskinan adalah kondisi ketidakmampuan pendapatan seseorang dalam pemenuhan kebutuhan pokok hidup sehingga tidak mampu menjamin kelangsungan hidupnya Kebutuhan hidup meliputi kebutuhan dasar seperti sandang, pangan, tempat tinggal, dan pendidikan. Menurut BPS, yang dikatakan penduduk miskin adalah penduduk yang memiliki rata-rata pengeluaran perkapita perbulan dibawah garis kemiskinan. Kabupaten Blitar adalah salah satu kabupaten di provinsi Jawa Timur. Angka kemiskinan di kabupaten Blitar mengalami penurunan sejak tahun 2016 hingga tahun 2019 dan mengalami kenaikan di tahun 2020. Langkah untuk mengetahui angka kemiskinan dihitung berdasarkan sampel survei analisis tingkat kemiskinan dalam survey Sosial - Ekonomi Nasional (Susenas) setiap 2 tahun sekali. Pengelompokan kemiskinan perlu dilakukan setiap tahunnya agar pemerintah dapat mengetahui langkah pencegahan agar kemiskinan tidak meningkat ataupun pemecahan masalah kemiskinan. Pengelompokan kemiskinan dapat dilakukan dengan menggunakan berbagai metode salah satunya adanya dengan menggunakan metode K-Means. Penggunaan metode K-Means ini bertujuan mengelompokkan data per kecamatan kabupaten Blitar yang tergolong penduduk miskin.
\end{abstract}

Kata Kunci: Kemiskinan, Kabupaten Blitar, K-Means

\section{Abstract}

Poverty is the inability of a person's income to fulfill the basic needs of life so that he is unable to guarantee his survival. The necessities of life include basic needs such as clothing, food, shelter, and education. According to BPS, what is said to be the poor are people who have an average monthly per capita expenditure below the poverty line. Blitar Regency is one of the regencies in East Java province. The poverty rate in Blitar district has decreased from 2016 to 2019 and has increased in 2020. The step to find out the poverty rate is calculated based on a sample of the poverty level analysis survey in the National Social-Economic Survey (Susenas) every 2 years. Poverty grouping needs to be done every year so that the government can find out preventive measures so that poverty does not increase or solve the problem of poverty. Poverty grouping can be done using various methods, one of which is the K-Means method. The use of the K-Means method aims to classify data per sub-district of Blitar Regency which is classified as poor.

Keywords: Poverty, Blitar Regency, K-Means

\section{Pendahuluan}

Kemiskinan adalah karakteristik variasi daerah. Kemiskinan dapat dilihat berdasarkan ketidakmampuan seseorang dalam segi perekonomian untuk memenuhi kebutuhan dasar seperti makanan maupun bukan makanan yang diukur bersandarkan pengeluaran [13]. Faktor seperti sering terjadinya bencana alam, letak geografis, akses pendidikan dan kesehatan, pembangunan infrastruktur, peluang ketenagakerjaan adalah sebagian penyebab kemiskinan [1]. Populasi penduduk di Kabupaten Blitar sejak tahun 2018 hingga 2020 terus mengalami kenaikan. Tahun 2019 jumlah penduduk laki-laki di kabupaten Blitar sebanyak 582.481 orang dan penduduk perempuan sebanyak 350.287 orang. Kepadatan penduduk ini merupakan suatu masalah yang banyak menimbulkan dampak bagi kehidupan sosial ekonomi masyarakat. Dampak yang ditimbulkan seperti sulitnya mencari peluang kerja, pengangguran meningkat, dan segala jenis kebutuhan fasilitas sosial juga meningkat. 
Kabupaten Blitar merupakan salah satu kabupaten yang berada di provinsi Jawa Timur. Pusat pemerintahannya terletak di kecamatan Kanigoro. Kabupaten Blitar memiliki luas wilayah sebesar 1.588,79 km². Secara administratif, kabupaten Blitar memiliki 22 kecamatan dengan 248 desa/ kelurahan. Adapun 22 kecamatan yang ada di kabupaten Blitar adalah Panggungrejo, Bakung, Sutojayan, Kademangan, Kanigoro, Garum, Talun, Selopuro, Wlingi, Kesamben, Selorejo, Doko, Nglegok, Sanankulon, Ponggok, Srengat, Wonodadi, Wonotirto, Binangun, Gandusari, Wates, dan Udanawu. Tingkat kemiskinan bersandarkan survei badan pusat statistik (BPS) tahun 2019 di Kabupaten Blitar mencapai 103,75 ribu jiwa (8.94\%) [3]. Menurut BPS yang dimaksud penduduk miskin adalah orang yang kemampuan ekonominya berada diambang garis kemiskinan. Jenis garis kemiskinan ada dua yaitu garis kemiskinan makanan ( $\mathrm{G} \mathrm{K} \mathrm{M}$ ) dan garis kemiskinan non makan (G K N M) yang menjadi indikator pengukuran tingkat kemiskinan. GKM merupakan nilai terkecil untuk kebutuhan bahan makanan. Sedangkan GKNM merupakan kebutuhan seperti hunian, pakaian, makanan, pendidikan, dan kesehatan. Kategori penduduk miskin dapat diketahui berdasarkan variable kemiskinan yang meliputi kepemilikan kekayaan, hewan ternak, status perkawinan, jenjang pendidikan kepala keluarga dan pasangan, kebutuhan pangan dan kesehatan [2].

Badan pusat statiska (BPS) menganalisa tingkat kemiskinan yang bersandarkan hasil survey Sosial - Ekonomi (Susenas) yang dilakukan tiap dua tahun sekali. Hasil pengukuran kemiskinan diambil berdasarkan sampel survey kurang merata karena tidak menghasilkan suatu ukuran pada tingkat terendah seperti kelurahan. Pengumpulan data diambil sesuai blok sensus. Blok sensus adalah daerah kerja bagi petugas pecacah survey BPS.

Salah satu permasalahan kemiskinan yang belum terselesaikan adalah hasil survey yang diberikan pemerintah tidak sesuai dengan kebutuhan penduduk. Kesulitan dalam proses penanganan kemiskinan oleh pemerintah adalah program bantuan sosial yang ditargetkan pemerintah kurang tepat sasaran. Hal ini disebabkan karena validasi data yang sering diabaikan sehingga sering menimbulkan data yang kurang akurat. Pengumpulan dan pengukuran data ini mengundang peneliti untuk mengkaji data secara lebih akurat agar pelaksanaan program bantuan sosial yang digunakan untuk mengatasi kemiskinan merata, berguna, dan tepat sasaran. Penulis menerapkan metode Algoritma K-Means Clustering. Penggunan metode K-Means ini bertujuan mengelompokkan data per kecamatan kabupaten Blitar yang tergolong penduduk miskin.

Prosedur K-Means dilakukan dengan cara: (1) penetapan kelompok. (2) mengalokasikan data pada kelompok. (3) menghitung centroid disetiap kelompok yang sudah ditentukan. Letak centroid diperoleh dari nilai tengah (mean) keselurahan data perkelompok. (4) peruntukkan tiap tiap data ke centroid terdekat. Menghitung jarak data ke tiap titik pusat cluster menggunakan teori jarak Euclidean dengan Persamaan 1.

$$
D e=\sqrt{(x i-s i)^{2}+(y i-t i)^{2}}
$$

Pengalokasikan ulang data pada tiap - tiap kelompok dalam K-Means yang bersandarkan perbandingan jarak antara data ke centroid pada kelompok [11].

Penelitian terdahulu yang relevan adalah penelitian yang dilakukan oleh Nanda dan Faisal (2018) dengan judul Penerapan Metode K-Means Pemetaan Calon Penerima JAMKESDA. dari penelitian tersebut dihasilkan bahwa metode K-Means dapat diterapkan untuk pemetaan masyarakat berdasarkan tingkat kemiskinan di kelurahan Kemuning, pada proses pengelompokkan sampel data yang digunakan sebanyak 440 dan didapatkan 2 cluster yang divalidasi menggunakan Davies Bouldin Index (DBI). berdasarkan hasil pengelompokkan tersebut sebanyak 334 anggota termasuk kedalam kelompok idak mampu dan 106 anggota kelompok mampu. Penelitian terdahulu yang relevan berikutnya adalah penelitian yang dilakukan oleh Nayuni, dkk (2020). Penelitian tersebut berjudul "Penerapan Algoritma K-Means dalam Menentukan Tingkat Penyebaran Pandemi Covid-19 di Indonesia". Berdasarkan penelitian tersebut didapatkan hasil bahwa algoritma $K$-means dapat menentukan pusat cluster yaitu cluster pertama berada pada provinsi DKI Jakarta, cluster kedua provinsi Jawa Barat, dan cluster ketiga provinsi Banten. Pusat cluster pertama adalah daerah penyebaran Covid 19 terbesar di Indonesia dengan kasus positif dan meninggal terbanyak.

REPOSITOR, Vol. 4, No. 1, Februari 2022: 49-58 


\section{Metode Penelitian}

Langkah-langkah pada penelitian ini tersusun sesuai Gambar 1 berikut:

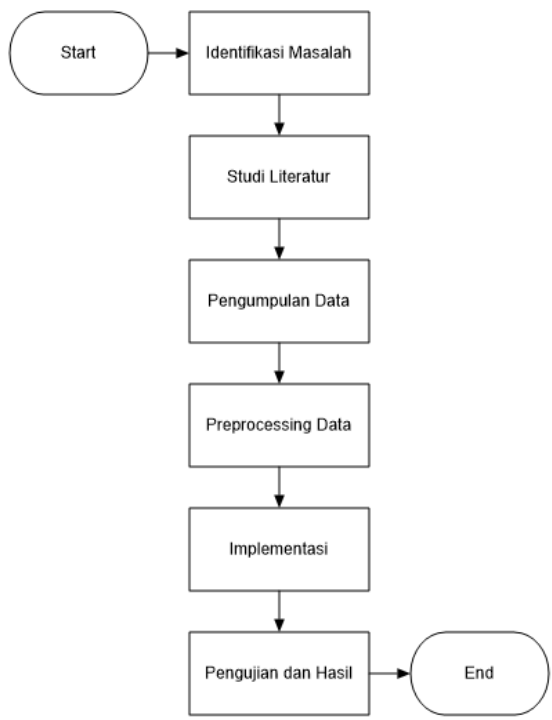

Gambar 1. Rancangan Penelitian

- Identifikasi Masalah

Langkah awal yang dilakukan dalam penelitian ini adalah mengidentifikasi masalah sebagai landasan awal untuk memahami dan menentukan solusi penyelesaian serta metode yang akan digunakan. Berdasarkan uraian yang sudah dijelaskan pada latar belakang, maka penulis memutuskan untuk mengangkat permasalahan kemiskinan di Kabupaten Blitar.

Salah satu permasalahan kemiskinan yang belum terselesaikan adalah hasil survey yang diberikan pemerintah tidak sesuai dengan kebutuhan penduduk. Kesulitan dalam proses penanganan kemiskinan oleh pemerintah adalah pembagian bantuan sosial yang tidak merata dan tidak tepat sasaran. Hal ini disebabkan karena validasi data yang sering diabaikan sehingga sering menimbulkan data yang kurang akurat. Penulis akan melakukan pendugaan/prediksi penduduk yang tergolong miskin dengan menghitung data yang diperoleh dari BPS dan PLN menggunakan metode K-Means. Penelitian ini diharapkan dapat menghasilkan klasterisasi penduduk yang tergolong miskin, sehingga pemerintah dapat mengetahui jumlah penduduk miskin per kecamatan di kabupaten Blitar. Hasil pengelompokan ini diharapkan menjadi bahan rujukan sebagai fokus untuk mengurangi permasalahan kemiskinan dan pemecahan masalah kemiskinan melalui program pemerintah seperti bantuan sosial dapat di distribusikan kepada penduduk miskin dengan baik dan tepat sasaran.

- Studi Literatur

Pada tahap ini akan dilakukan pemahaman tentang konsep dasar algoritma - algoritma yang digunakan dalam penelitian yang akan dilakukan. Adapun literatur yang digunakan adalah jurnal dan buku yang memiliki tema atau bahasan yang sesuai dengan penelitian yang akan dilakukan, yaitu tentang kemiskinan dan metode algoritma K-Means.

- Pengumpulan Data

Pada penelitian ini, data yang diperlukan berupa data yang diambil dari BPS dan PLN Kabupaten Blitar. Data diperoleh dari website resmi BPS Kabupaten Blitar. Data dari PLN diperoleh secara langsung dari kantor PLN Kabupaten Blitar.

\section{- Preprocessing Data}

Data yang telah didapatkan kemudian diolah sebelum memasuki proses klasifikasi. Pada tahap preprocessing ini, data mentah yang telah berhasil diambil pada tahapan sebelumnya akan diolah terlebih dahulu dikarenakan data yang diterima masih acak dan perlu di kelompokkan berdasarkan kebutuhan data yang akan diolah. Pada tahap ini dilakukan penentuan kolom yang akan dijadikan sebagai acuan dalam klasterisasi, pada penelitian ini kolom yang digunakan 
sebagai acuan untuk menentukan kluster tingkat kemiskinan kecamatan menggunakan kolom, "JKM", "PSS", "PLN", "KP", "SP".

Preprocessing berfungsi untuk mengeliminasi atau menghilangkan data yang tidak sesuai atau secara garis besar mengubah data tersebut agar lebih mudah diproses oleh system dengan kata lain tahapan ini adalah tahapan awal untuk menyetarakan data yang sudah berhasil dikumpulkan.

- Implementasi

Dari tahapan awal mengidentifikasi masalah, studi literatur, pengumpulan data, hingga preprocessing, kemudian data yang sudah melewati tahapan - tahapan sebelumnya akan diimplementasikan dengan metode $K$-Means.

- Pengujian dan Hasil

Proses pengujian pada penelitian ini akan dilakukan klasterisasi data dengan menggunakan tiga klaster yang dilabeli menggunakan "0", "1". Label tersebut akan menunjukkan nilai terendah sampai nilai tertinggi.

Hasil dari penelitian ini nantinya berupa hasil klasterisasi data akan digabungkan dengan variable-variabel kemiskinan dan akan diketahui hasil klasifikasi klaster berdasarkan jenis label yang diperoleh. Hasil klasterisasi kemudian divalidiasi menggunakan silhouette coeffisien untuk mengukur kualitas klaster.

\section{Analisa Kebutuhan Sistem}

Analisis kebutuhan sistem berisi tentang analisa kebutuhan perangkat keras dan perangkat lunak yang digunakan dalam penelitian ini. Adapun dalam penelitian ini menggunakan kebutuhan seperti pada Tabel 1 dan Tabel 2.

- Kebutuhan perangkat keras ( hardware)

Tabel 1. Tabel Kebutuhan Perangkat Keras

\begin{tabular}{cccc}
\hline No & Perangkat & Jumlah & Spesifikasi \\
\hline \multirow{2}{*}{1} & Laptop & 1 & Processor : Intel Pentium inside \\
& & & RAM : $2 \mathrm{~GB}$ \\
& & HDD : $320 \mathrm{~GB}$ \\
\hline
\end{tabular}

- Kebutuhan perangkat lunak ( software )

\begin{tabular}{cc}
\multicolumn{2}{c}{ Tabel 2. } \\
\hline No & Sabel Kebutware \\
\hline 1 & Sistem Operasi Windows 10 \\
2 & Python \\
4 & Micorosoft Word \\
5 & Microsoft Excel \\
\hline
\end{tabular}

\section{Hasil Penelitian dan Pembahasan}

\subsection{Data}

Data pada penelitian ini menggunakan data penduduk miskin tiap Kecamatan yang terdiri dari 22 Kecamatan di Kabupaten Blitar. Data tersebut mencakup:

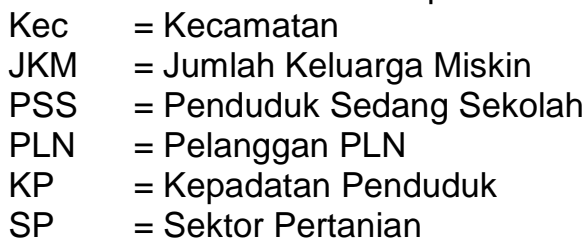

Data yang diperoleh telah berformat csv, data tersebut dibaca dengan menggunakan library pandas dan disimpan pada variable "data" seperti pada Gambar 2. 


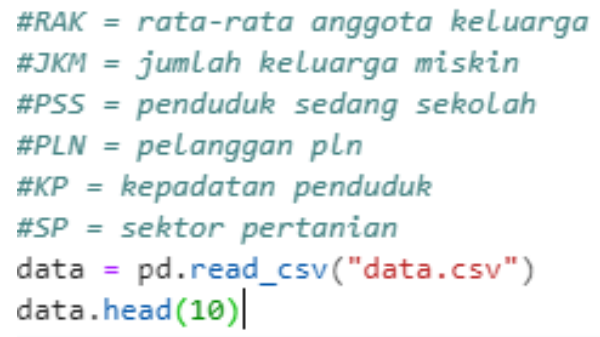

Gambar 2. Source Code Import Data

Pada variable "data" terdapat data kesuluruhan dan dapat ditampilkan 10 data teratas menggunakan fungsi "head()" seperti pada Gambar 3 berikut.

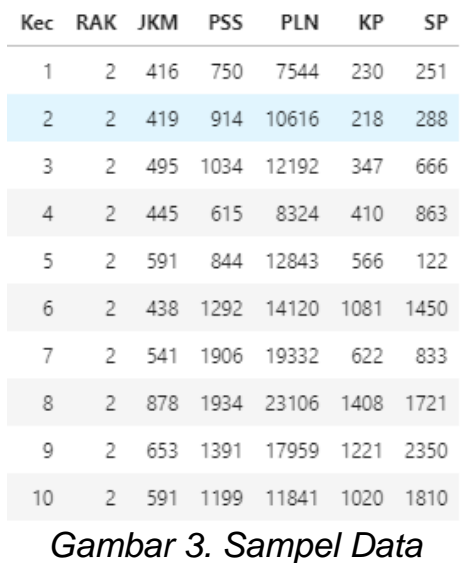

\subsection{Preprocessing Data}

Selanjutnya adalah menentukan kolom yang akan dijadikan sebagai acuan dalam klasterisasi, pada penelitian ini kolom yang digunakan sebagai acuan untuk menentukan klaster tingkat kemiskinan kecamatan menggunakan kolom, "JKM", "PSS", "PLN", "KP", "SP". Data tersebut akan dipisah dan dibentuk menjadi array dan disimpan dalam variable "clusterdata_array" seperti pada Gambar 4 berikut.

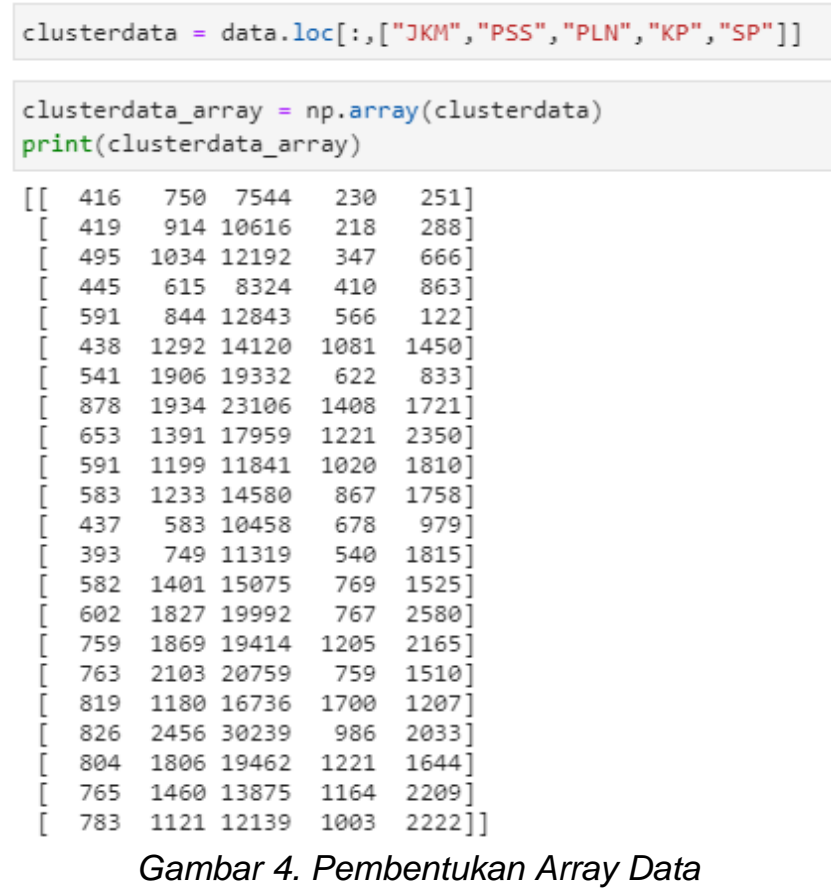


Langkah selanjutnya adalah data tersebut akan di normalisasi sebelum dihitung menggunakan metode klasterisasi. Normalisasi data dilakukan menggunakan "MinMaxScaler()" yang didapatkan dari library "sklearn.preprocessing" seperti pada Gambar 5 berikut.

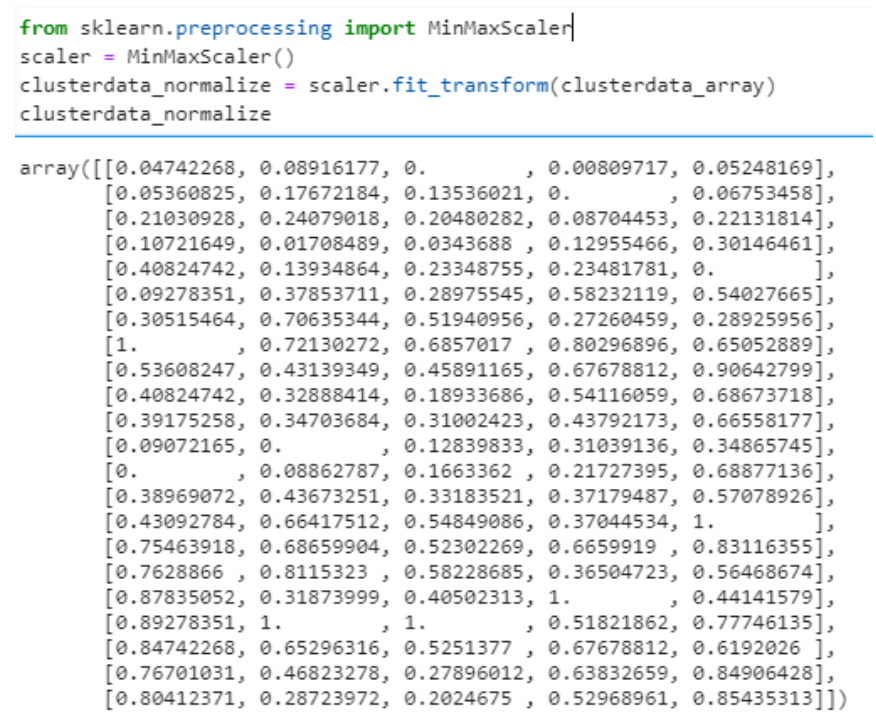

\section{Gambar 5. Normalisasi Data}

Berdasarkan gambar diatas menunjukkan source code dan hasil normalisasi data yang disimpan dalam variable "clusteredata_normalize".

\subsection{Klasterisasi Data}

Pada klasterisasi data yang pertama dilakukan adalah menguji berapa nilai klaster yang optimal dari sebuah data sebelum dibentuk menjadi sebuah klaster dengan menggunakan metode elbow, seperti pada Gambar 6 berikut.

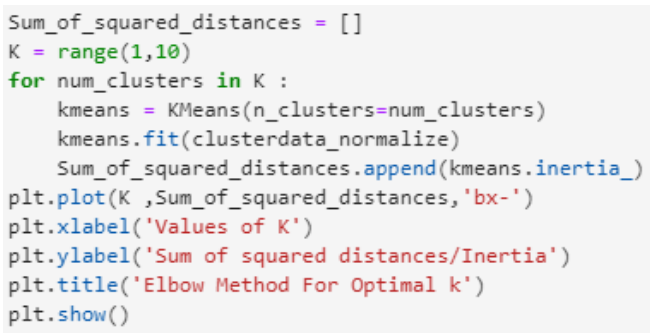

\section{Gambar 6. Pembentukan Grafik K}

Pada gambar diatas percobaan dilakukan dengan menjalankan klasterisasi K-Means pada dataset untuk rentan nilai $\mathrm{k}$ yang berbeda yaitu 1 sampai 9 untuk setiap $\mathrm{k}$ yang akan menghitung jarak rata-rata pada pusat cluster di semua data. Adapun hasil grafik sebagai berikut.

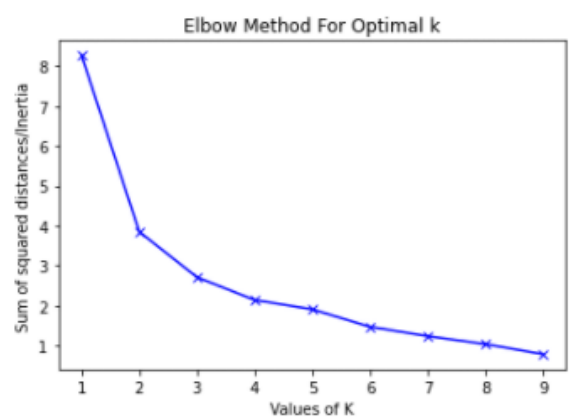

Gambar 7. Grafik K

REPOSITOR, Vol. 4, No. 1, Februari 2022: 49-58 
Pada Gambar 7 diatas dapat dilihat grafik dari masing masing k, berdasarkan gambar tersebut dapat diketahui bahwa nilai $\mathrm{k}$ yang paling baik untuk digunakan adalah dalam klasterisasi dengan menggunakan $\mathrm{k}=2$, karena pada nilai $\mathrm{k}=2$ terdapat kuadran yang turun secara tiba-tiba hingga membentuk sudut yang lebih dekat dengan siku-siku dibandingkan dengan kuadran yang lain.

Selanjutnya dilakukan uji coba menggunakan nilai silhouette coefficient pada setiap k untuk menentukan nilai $\mathrm{k}$, silhouette coefficient yang akan menentukan kemiripan satu titik data dalam cluster dibandingkan dengan cluster lain, Adapun source code perhitungan silhouette coefficient seperti pada Gambar 8 berikut.

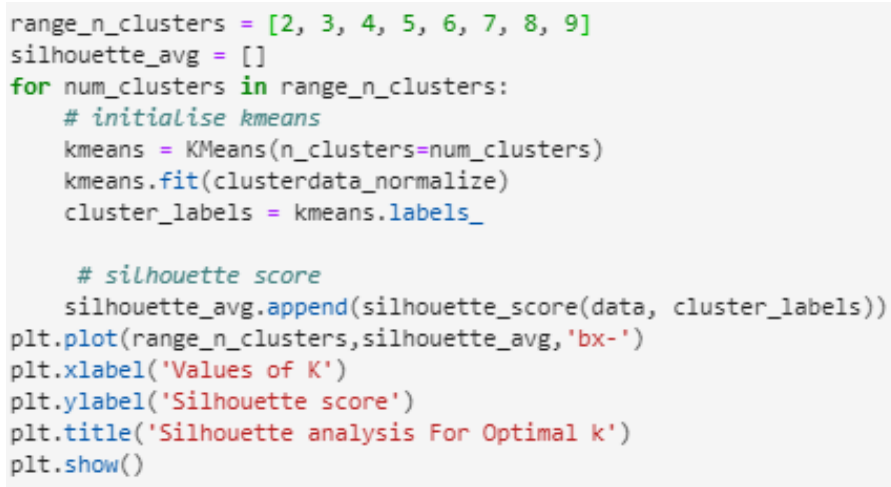

Gambar 8. Source Code Silhouette Coefficient

Pada gambar diatas menunjukkan pengujian silhouette coefficient pada rentan nilai 2 sampai 9 pada setiap nilai $k$ dan menghasilkan sebuah plot pada grafik seperti pada Gambar 9 berikut.

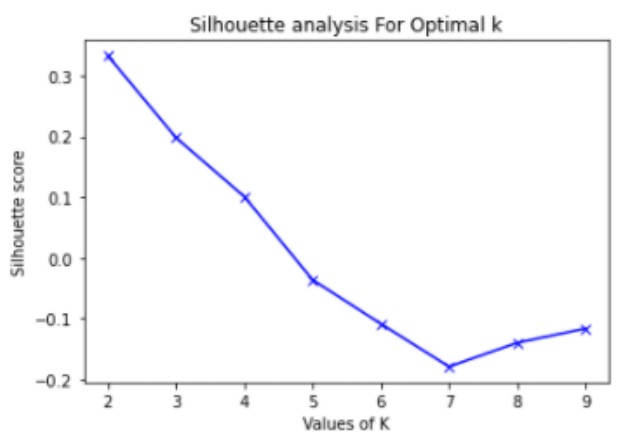

Gambar 9. Grafik Silhouette Coefficient

Pada gambar diatas menunjukkan hasil grafik dari nilai silhouette coefficient, nilai rentan silhouette coefficient berada diantara $[-0.2,0.33]$. pada pengujian silhouette coefficient nilai yang mendekati satu menunjukkan titik terbaik atau nilai k terbaik untuk digunakan dalam klaterisasi. Berdasarkan grafik tersebut nilai $\mathrm{k}$ yang baik berada pada $\mathrm{k}=2$ karena nilai silhouette coefficientnya mendekati nilai 1.

Berdasarkan 2 pengujian diatas dapat disimpulkan nilai $\mathrm{k}$ yang baik digunakan dalam clusterisasi data adalah dengan menggunakan nilai $\mathrm{k}=2$, selanjutnya klasterisasi data dilakukan pada data dengan nilai $\mathrm{k}=2$ seperti pada Gambar 10 berikut.

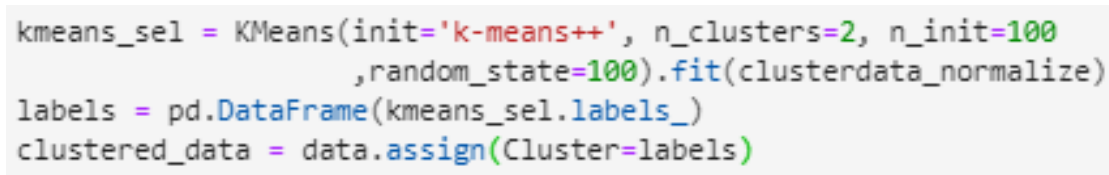

Gambar 10. Klasterisasi Data 
Berdasarkan gambar diatas dapat diketahui bahwa hasil klasterisasi dibentuk kedalam data frame dengan menggunakan library pandas dan kemudian digabungkan kedalam "data" untuk mengetahui data yang masuk kedalam masing-masing klaster. Adapun hasil klasterisasi data sebagai berikut.

\begin{tabular}{|c|c|c|c|c|c|c|c|c|}
\hline & Kec & RAK & JKM & PSS & PLN & KP & SP & Cluster \\
\hline 0 & 1 & 2 & 416 & 750 & 7544 & 230 & 251 & 0 \\
\hline 1 & 2 & 2 & 419 & 914 & 10616 & 218 & 288 & 0 \\
\hline 2 & 3 & 2 & 495 & 1034 & 12192 & 347 & 666 & 0 \\
\hline 3 & 4 & 2 & 445 & 615 & 8324 & 410 & 863 & 0 \\
\hline 4 & 5 & 2 & 591 & 844 & 12843 & 566 & 122 & 0 \\
\hline 5 & 6 & 2 & 438 & 1292 & 14120 & 1081 & 1450 & 0 \\
\hline 6 & 7 & 2 & 541 & 1906 & 19332 & 622 & 833 & 0 \\
\hline 7 & 8 & 2 & 878 & 1934 & 23106 & 1408 & 1721 & 1 \\
\hline 8 & 9 & 2 & 653 & 1391 & 17959 & 1221 & 2350 & 1 \\
\hline 9 & 10 & 2 & 591 & 1199 & 11841 & 1020 & 1810 & 0 \\
\hline 10 & 11 & 2 & 583 & 1233 & 14580 & 867 & 1758 & 0 \\
\hline 11 & 12 & 2 & 437 & 583 & 10458 & 678 & 979 & 0 \\
\hline 12 & 13 & 2 & 393 & 749 & 11319 & 540 & 1815 & 0 \\
\hline 13 & 14 & 2 & 582 & 1401 & 15075 & 769 & 1525 & 0 \\
\hline 14 & 15 & 2 & 602 & 1827 & 19992 & 767 & 2580 & 1 \\
\hline 15 & 16 & 2 & 759 & 1869 & 19414 & 1205 & 2165 & 1 \\
\hline 16 & 17 & 2 & 763 & 2103 & 20759 & 759 & 1510 & 1 \\
\hline 17 & 18 & 2 & 819 & 1180 & 16736 & 1700 & 1207 & 1 \\
\hline 18 & 19 & 2 & 826 & 2456 & 30239 & 986 & 2033 & 1 \\
\hline 19 & 20 & 2 & 804 & 1806 & 19462 & 1221 & 1644 & 1 \\
\hline
\end{tabular}

Pada Gambar 11 diatas menunjukkan sebagian data hasil klasterisasi dengan $\mathrm{k}=2$, kolom "Cluster" menunjukkan data tersebut termasuk kedalam klaster 0 atau 1. Langkah selanjutnya untuk membagi data berdasarkan klaster dapat dilakukan dengan menggunakan source code berikut.

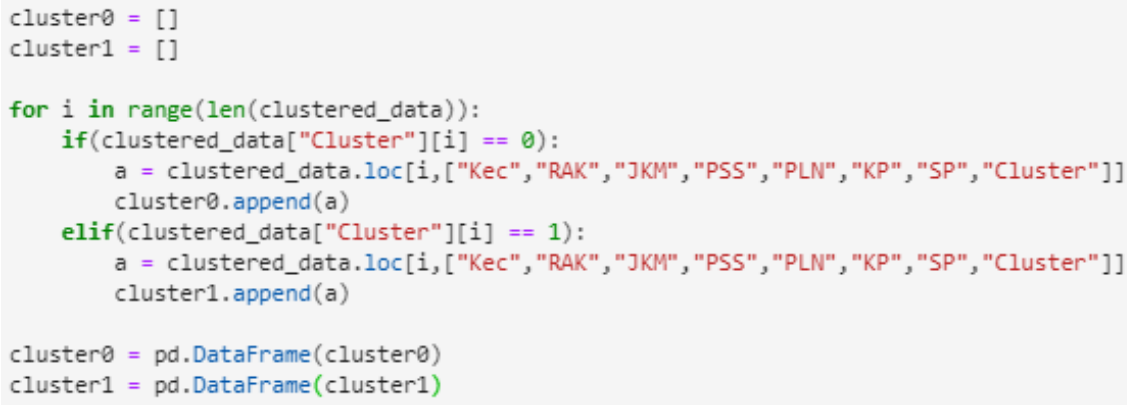

Gambar 12. Pembagian Data berdasarkan Klaster

Pada Gambar 12 diatas jika kolom "Cluster" menunjukkan 0 maka data akan dimasukkan kedalam variable "cluster0" yang kemudian data tersebut dirubah menjadi dataframe dan menghasilkan bentuk data seperti berikut. 


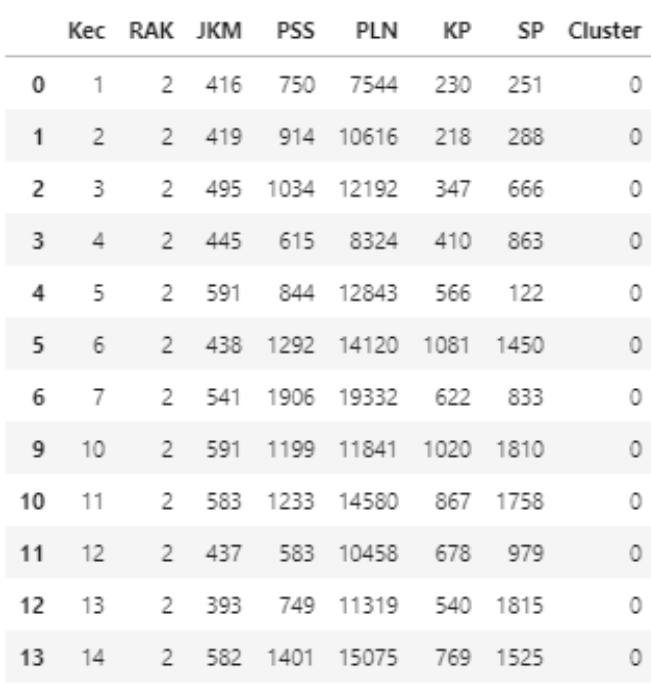

Gambar 13. Klaster ke "0"

Berdasarkan Gambar 13 diatas menunjukkan semua data yang termasuk dalam klaster "0" yaitu data pada kecamatan 1, 2, 3, 4, 5, 6, 7, 10, 11, 12, 13, 14. Berdasarkan gambar diatas yang termasuk kategori penduduk miskin adalah kecamatan - kecamatan berikut: Bakung, Wonotirto, Panggungrejo, Wates, Binangun, Sutojayan, Kademangan, Selopuro, Kesamben, Selorejo, Doko, dan Wlingi.

Kemudian jika kolom "cluster" menunjukkan 1 maka data akan dimasukkan kedalam variable "cluster1" yang kemudian data tersebut dirubah menjadi dataframe dan menghasilkan bentuk data seperti berikut.

\begin{tabular}{rrrrrrrrr} 
& Kec & RAK & JKM & PSS & PLN & KP & SP & Cluster \\
\hline 7 & 8 & 2 & 878 & 1934 & 23106 & 1408 & 1721 & 1 \\
8 & 9 & 2 & 653 & 1391 & 17959 & 1221 & 2350 & 1 \\
14 & 15 & 2 & 602 & 1827 & 19992 & 767 & 2580 & 1 \\
15 & 16 & 2 & 759 & 1869 & 19414 & 1205 & 2165 & 1 \\
16 & 17 & 2 & 763 & 2103 & 20759 & 759 & 1510 & 1 \\
17 & 18 & 2 & 819 & 1180 & 16736 & 1700 & 1207 & 1 \\
18 & 19 & 2 & 826 & 2456 & 30239 & 986 & 2033 & 1 \\
19 & 20 & 2 & 804 & 1806 & 19462 & 1221 & 1644 & 1 \\
20 & 21 & 2 & 765 & 1460 & 13875 & 1164 & 2209 & 1 \\
21 & 22 & 2 & 783 & 1121 & 12139 & 1003 & 2222 & 1
\end{tabular}

Gambar 14. Klaster ke "1"

Pada Gambar 14 diatas menunjukkan semua data yang termasuk dalam klaster "1" yaitu data pada kecamatan 8, 9, 15, 16, 17, 18, 19, 20, 21, 22.

\section{Kesimpulan}

Berdasarkan hasil penghitungan menggunakan metode $K$-Means, maka diketahui hasil dan dapat disimpulkan sebagai berikut:

1. Pengelompokkan kecamatan - kecamatan dengan penduduk miskin diketahui berdasarkan variabel jumlah keluarga miskin, penduduk sedang sekolah, pelanggan PLN, kepadatan penduduk, dan sektor pertanian.

2. Jumlah sampel yang digunakan sebanyak 22 kecamatan di Kabupaten Blitar dan menghasilkan 2 klaster yaitu klaster 0 dan klaster 1 . 
3. Metode K-Means dapat digunakan untuk mengelompokkan penduduk miskin per kecamatan di kabupaten Blitar.

4. Berdasarkan hasil klasterisasi, data klaster 0 adalah kecamatan yang dikelompokkan sebagai kecamatan dengan penduduk miskin di Kabupaten Blitar.

\section{Daftar Notasi}

Contoh penulisan notasi dapat diuraikan dengan keterangan sebagai berikut:

$\mathrm{De}=$ Eucliedean Distance

I = jumlah objek

$(\mathrm{x}, \mathrm{y})=$ Koordinat Object

$(\mathrm{s}, \mathrm{t})=$ Koordinat Centroid

\section{Referensi}

[1] M. Y. Darsyah and R. Wasono, "Pendugaan Tingkat Kemiskinan di Kabupaten Sumenep dengan Pendekatan SAE."

[2] W. Isdijoso and A. Suryahadi, "Penetapan Kriteria dan Variabel Pendataan Penduduk Miskin yang Komprehensif dalam Rangka Perlindungan Penduduk Miskin di Kabupaten / Kota."

[3] BPS Kabupaten Blitar. "Jumlah dan Persentase Penduduk Miskin dan Garis Kemiskinan Menurut Kabupaten Kota di Jawa Timur." https://www.bps.go.id/indicator/23/621/1/persentase-penduduk-miskin-menurut-kabupatenkota.html (3 Januari 2020).

[4] Nasution, Irmanita., Windarto, Agus Perdana., Fauzan, M, "Penerapan Algoritma K-Means Dalam Pengelompokan Data Penduduk Miskin Menurut Provinsi". Volume 2, No,2 Desember 2020.

[5] Suryawati. 2004. Teori Ekonomi Mikro. UPP. AMP YKPN. Yogyakarta: Jarnasy

[6] Suhartini., Yuliani, Ria, "Penerapan Data Mining untuk Mengcluster Data Penduduk Miskin Menggunakan Algoritma K-Means di Dusun Bagik Endep Sukamulia Timur". Vol.4 No. 1 Januari 2021.

[7] Nurwati, Nunung, "Kemiskinan: Model Pengukuran, Permasalahan dan Alternatif Kebijakan". Vol. 10, No.1, Januari 2008.

[8] Nazara, Suahasil. 2007. "Pengentasan Kemiskinan : Pilihan Kebijakan dan Program yang Realitis" Dalam Wara Demografi tahun ke 37. No 4 tahun 2007. Jakarta. Lembaga Demografi Universitas Indonesia. Pengangguran, Kemiskinan, dan Pertumbuhan Ekonomi Indonesia.

[9] Kemsos. "UU 13 Tahun 2011 - Pusat Penelitian dan Penanganan Fakir Miskin" https://puslit.kemsos.go.id/upload/aturan/files/f5c497935cc2794803aa5f91c3f2404e.pdf (15 Desember 2019)

[10] Aras, Zainul., Sarjono, "Analisis Data Mining untuk Menentukan Kelompok Prioritas Penerima Bantuan Bedah Rumah Menggunakan Metode Clustering K-Means (Studi Kasus: Kantor Kecamatan Bahar Utara)" Vol 1 No.2, Desember 2016.

[11] Dhuhita, Windha Mega, "Clustering Menggunakan Metode K-Means untuk Menetukan Status Gizi Balita" Vol. 15, No.2, Desember 2015.

[12] Anggara, Mario., Sujiani, Herry., Nasution, Helfi, "Pemilihan Distance Measure pada KMeans Clustering untuk Pengelompokkan Member di Alvaro Finess" Vol. 1, No. 1, 2016.

[13] BPS "Kemiskinan dan Penduduk Miskin" https://www.bps.go.id/subject/23/kemiskinan-danketimpangan.html (7 Juli 2021)

[14] BPS "Kemiskinan dan Ketimpangan" https://jatim.bps.go.id/indicator/12/375/1/jumlahpenduduk-provinsi-jawa-timur.html (7 Juli 2021)

[15] Arif Muttaqien, Paradigma Baru Pemberantasan Kemiskinan, Rekonstruksi Arah Pembangunan Menuju Masyarakat Yang Berkeadilan, Terbebaskan Dan Demokratis, (Jakarta; Khanata Pustaka LP3ES Indonesia, 2006), dikutip oleh Istiana Herawati , "Dampak Program Pengentasan Kemiskinan Dampak Program Pengentasan Kemiskinan Di Kabupaten Jayapura", (Jurnal Penelitian dan Evaluasi Pendidikan BP2P3KS Kementerian Sosial RI), h. 146

REPOSITOR, Vol. 4, No. 1, Februari 2022: 49-58 